\title{
AN ARGUMENT FOR FREEDOM OF CHOICE
}

David E. Kyvig

The University of Akron

Historians, intellectually committed in their research and writing to the principle that a wide range of approaches have validity in seeking to understand the past, very often have failed to apply the same reasoning in their classrooms. The historian who believes that tape-recorded memoirs, quantification, traditional archival sources, psychologists' methods, and photographs all offer means of evaluating some bygone individual or event is often the teacher who sets forth a rigid program of work for students in his or her class. The nature of the assignment may vary from examination to research paper to book review to imaginative and unusual project, but the common practice is to expect all students in a course to undertake the same type of work (with possibly one assignment made optional). An experiment with a different approach to student work in several history courses at the University of Akron appears academically sound, has been greeted enthusiastically by students, and, therefore, seems worthy of consideration.

My desire to find an alternative to traditional methods of assigning work for students began at least as early as my first effort to organize a history course. I offer a variety of courses in American history--an introductory survey and advanced courses in twentieth century and diplomatic hism tory--to students with differing levels of sophistication, intellect, and motivation at a large, state-supported, urban university. Faced with a diverse constituency in every class, I again and again confronted the common problem: what type of work can I ask for which will encourage historical learning and serve the needs of each student? If, as I assume, the most significant and lasting learning occurs when a student is enthusiastic about his or her work, it is crucially important to provide an opportunity for that student to engage in the sort of activity he or she finds appealing. However, with some students taking their first work in American history, with others entering the same course with a substantial background, and with all having individual talents and interests, it is difficult--I would even contend impossible--to find a single pattern of work assignments which will be attractive to all members of the same class.:- Furthermore, it is seldom possible to predict with any certainty the make-up of a new class in order to lay out a program of work at least generally suited to the students' special circumstances.

of course, under a tutorial program with a one-on-one student-teacher relationship and an opportunity to design activities particularly suited to the individual's evolving needs, no problem would exist. Unfortunately for all concerned, the vast numbers of persons seeking to learn (some cynics would say seeking to obtain degrees) and the various limitations on educational resources dictate that most formal academic training will take place in groups, often rather large groups. The memory of Mark Hopkins sitting on one end of a $\log$ with his pupil on the other will, regrettably, remains nothing more than a fond image, regularly recalled by instructors grumbling over their coffee about the number of students being squeezed into their classes. Providing instruction suitable to the needs of the individual within sizeable classes will remain a perennial dilemma for conscientious teachers.

In trying to cope with the problems of course design, I was influenced not only by the previously-mentioned considerations, but also by my own nottoo-distant empirical experience as a student. Even in the best of courses, the assignments often failed to meet my special needs or interests, and, if they did, then many of my classmates were ill-served. The course in which I moitld have 1iked to investigate a particular topic in depth often demanded 
a heavy workload of other sorts so that the research remained undone. Or the opposite occurred: where I sought a broad, general knowledge, the thrust of the course Involved a narrow research paper. Doubtless one could justifiably say, "We11, he should have pursued these interests on his own." But a student's time and energy have limits, and it does not seem unreasonable to expect academic programs to seek to make the best use of them.

More than anything else, a sense that as a professor I lacked sufficient wisdom to predict correctly what would be best for every student who chose to enter my courses led me to experiment with a system which allows the individual student a completely free choice as to the nature of his or her work for me. My course syllabus for the introductory survey of American history and advanced courses now contains the following statement, or something similar:

In this course, each student is expected to do the assigned readings, attend classes, and particlpate in discussions. Beyond these bastc requirements, students may determine for themselves, according to their preference, the type of work they will do and upon which they will be evaluated. Students are obligated to undertake 100 points worth of work and may choose from among the following options:

25 points: M1d-term examination, a one-hour, written essay exam.

25 polnts: Crftical book review. This should conslst of a brief summary of the book's contents and a careful analysis of the book's major themes, its strengths and weaknesses, the evidence upon which it is based, the author's biases, blind-spots, and qualffications, the quality of the writing, etc. A student may do up to three reviews for 25 points each. The (assigned monographs, novels, etc.) may be used or another sultable book may be chosen in consultation with the instructor. Reviews of books scheduled to be discussed In class will be due at the outset of those discussions, and other reviews will be due the last week of the term.

25 points: Essay. A paper of approximately 500 to 1000 words on a question relating to one of the assigned readings.

(Questlons dealing with spectfic issues raised in each of the books which may be used are listed.) A student may do two of these for 25 points each. Essays are due at the outset of the class session in which the reading involved is scheduled to be discussed.

35 points: Oral classroom presentation. This may take the form of leading a class discussion of one of the assigned readings (initiating and gulding discussion on significant aspects of the material as well as offering one's own critical observations) or it may involve the presentation of research on a topic selected in consultation with the instructor. In either case, for scheduling purposes and because only a limited number of such opportunities will be available, it is necessary that the student indicate as early as possible his intention of taking this option.

50 points: Term paper. Toplc to be chosen in consultation with instructor no later than the end of the fourth week of the term. A bibliography of materials consulted is required, and standard footnoting procedures should be observed. Due last week of term. 
50 points: Family history. A social history of the student's grandparents and parents to be done according to a guide available from the instructor. Due last week of term. (This option, available only in survey and advanced courses dealing with twentieth century America, involves a project quite similar to that described in David H. Culbert, "Undergraduates as Historians: Family History Projects Add Meaning to an Introductory Survey," The History Teacher VII, (November 1973), 7-17.)

? Points: Final examination, either a two-hour written essay exam or a one-half to one-hour oral according to the student's preference. The student may select the point value to be assigned on the final, up to a maximum of 50 points.

If a student wishes to pursue some other sort of project which he or she can justify in relation to this course, the instructor will be happy to consider it and, if approved, assign appropriate point value to it.

Further details will be given and other procedural natters will be discussed at the first class meeting and, as necessary, throughout the term.

Not one of the options among those listed is either unique or singularly valuable. Quite obviously, they reflect the sorts of assignments that history teachers throughout the country have been giving their students for years. The sole non-traditional aspect of this approach lies in offering the student a free choice of several alternative learning patterns. It is this principle of student choice from among a considerable range of work possibilfties which may render this system useful to teachers, especially those in fields such as history where a wide variety of skills and intellectual approaches have validity. Any of the various options presented could be modified, replaced, or dropped altogether without serious loss as long as the element of substantial choice remains. If the idea of student choice of work is accepted as academically sound, the difficulties of implementing such a system are minor.

Once instructors can master their apprehension at the idea of each student in a college class possibly doing something unlike any other student (which, after all, is a situation that most reasonably progressive firstgrade teachers have been successfully coping with for some time under much more harrying circumstances), the choice-of-work plan does not present many problems, although it may pose a few. Above a11, the cholce-of-work system does not inherently involve any abandonment of standards of expected performance, termination of responsibility for advising or instruction, or relaxation of systems of evaluation. A refusal to assume that one knows what particular learning devices are best for every student does not mean that one rejects the idea that careful study and hard work are beneficial. Quite the contrary, it is the belief that learning requires strenuous effort which underlies the attempt to provide opportunities for students to work on projects which motivate them. Careful selection of the options to be offered and sound, conventional procedures in conducting the course can insure its rigor and value.

The amount and quality of work expected of a student under the choice-ofwork system is, as always, up to the instructor. Either by directly indicating how much effort should be invested in a particular task or through setting point values for individual options and the total work requirement, an 
instructor may be as demanding as he or she wishes. If there is a desire to encourage certain types of work while still permitting the student to choose otherwise, an instructor may inflate or deflate the relative point value of an option to make it more or less attractive.

In carrying out particular tasks, the student can work as independently or under as close supervision as the instructor wishes. A notable benerit the choice-of-work system in regard to advising students on their work is the virtual elimination of those difficult situations in which a student has no idea of how to proceed with a required assignment. Instead the instructor converses with students eager to talk about work they have chosen to do because it interests them and because they can cope with it. One drawback of the system is that often there is difficulty in spotting the student with serious academic deficiencies early in the term. If a student chooses to elect options where assignments are not due until late in the course, problems may not come to light until it is too late to render significant assistance. This places some responsibility upon the instructor to discuss projects with students during their preliminary phases, but above all it requires students to face their weaknesses and seek assistance. If students and instructors are conscious of such pitfalls in the choice-of-work system, they should be able to cope with problems as well as under any other course format.

Evaluation of student performance can be conducted in rather traditional fashion under the choice-of-work system. Unlike some other innovative approaches to course work and its evaluation, in which a student may determine how much work he or she will undertake and make a "contract" for a particular grade if the work is satisfactorily completed, or continue to turn in additional work to accumulate more credit, or resubmit an assignment to raise a grade, the choice-of-work plan is not intended to provide an open-ended opportunity for the student. Individual pieces of work are judged for quality and then weighted to the final grade according to the relative point value of the option involved. A student choosing to undertake more than the required amount of work in a course simply finds each completed project representing a smaller portion of the overall grade. For instance, a student who elected to do 150 points worth of work would find his 50 point term paper representing one-third of the final grade. While not seeking to penalize the unusually industrious student, this approach assumes that an adequate amount of work has been requested in the first place and that performance should be judged on the basis of quality rather than quantity. Students are told--though instinctive "gamesmanship" leads most to discover this on their own quickly--that

they are better off doing the required amount of work well rather than spreading their efforts over a greater number of tasks. Of course, if an instructor prefers to reward extra output, this can be done very simply, but the more conservative approach helps those students who are tempted to spread themselves thinly over a variety of appealing possibilities to focus their efforts on a few tasks from among the wide range of avallable alternatives.

As under any other approach, evaluation under the choice-of-work system can break down if the instructor lacks a clear sense of his or her own standards and level of expectation. Student performance cannot be evaluated simply by comparing. the work of one student with that of others on the same assignment. With each student in a class conceivably selecting options individually and in combinations unlike those chosen by any other student, the instructor must rely upon his or her own sense of what constitutes superior, average, or inferior quality work in arriving at an evaluation. For this reason, the choice-of-work may possibly not be appropriate for the inexperienced instructor who has not had the opportunity to examine a sufficiently wide variety of student work to develop a stable and strong sense of his or her own standards. 
The presence of master's degree candidates in courses intended primarily for upper-division undergraduates is a fairly common, if somewhat unfortunate situation in many institutions. In such cases, the question always arises as to what should be expected of the M.A. student compared to the undergraduate. One solution under the choice-of-work system is to require both more work (130 points as opposed to the undergraduate's 100 has proven a reasonable differential) and higher quality performance. Other means of coping with this problem could certainly be devised within the flexible framework of the choice plan. In any case, the master's student in such courses may well be the greatest benefictary of the choice-of-work system, in that the student is freed from the necessity of having once again to do the sorts of assignments encountered many times before and is allowed to devise a program suited to his or her more specialized needs.

Any approach to course organization which avolds the imposition upon student's of a single, possibly eccentric, pedagogical approach and at the same time allows the possibility of maintaining a reasonable level of academic quality probably needs no further justification in this day and age. Yet the choice-of-work system has other attractive attributes, not the least of which is the enthusiasm for it registered by the students. Anonymous course evaluations returned by 116 students in six different classes produced only three negative appraisals of the system. One critic doubted that grading judgments could be fairly made when students did different types of work; another felt that a person who concentrated on a single topic in a research pàper would enjoy an advantage over the individual trying to synthesize a term's worth of knowledge on an exam; and a third said, "I prefer regulated requirements such as all taking all exams, but like the choice of writing a term paper." An overwhelming percentage of respondents endorsed the system, repeatedly using the terms "fair," "flexible," and, in the hyperbole of the day, "fantastic." One student wrote, "I am very pleased with the opportunity given students to choose their own destiny," while another called the plan "an incentive to the student. He sees what is to be done at the beginning of the course--what is expected of him--knows what to do and how to go about 1 t--and can work from there-also prevents the student from waiting until the last minute to get things for his course done." One student liked the chance to "choose your own poison." A final comment suggests the importance of the image created by the choice-of-work system. "L1ttle things like being able to select grading methods terid to make students feel a professor has a desire to be fair."

The choice-of-work system was consciously designed to allow students to concentrate on their strong points and avold tasks at which they feel they do badly. For instance, it is possible to entirely avoid taking examinations by choosing to write papers or do other projects; conversely one can avoid writ*. ing papers altogether by choosing to do examinations and oral presentations. There are enough options available so that any one particular assignment can easily be evaded. While it may be argued that a student should be helped to improve those skills which are weak-rapid response on examinations, preparation of formal papers, oral presentation, or whatever--it makes just as much sense to refine and further strengthen his or her greatest abilities, on the theory that he or she is much more likely to be using these in later life. In any case, the student should have the liberty to decide whether to concentrate on his or her strengths or weaknesses. While most do choose the sort of work they feel they do the best, a refreshing number are willing to undertake projects $1 \mathrm{n}$ areas of weakness or inexperience. Not surprisingly, a number of students commented in their evaluations that they enjoyed being able to avoid traditional examinations, but one admitted, "I found that even not being made to take a test, I did anyway without pressure because I wanted to." Given the opportunity, students will more than likely pursue options which they perceive as being. 1n their own best interests. 
While the system does appeal to students and does allow them to select a work program they consider advantageous, at the same time it demands a considerable degree of initiative on their part. Not only must the student choose his or her options, but once this is done, he or she must exercise sufficient self-discipline to complete the work. It is relatively difficult for the instructor to identify the sţudent who is not doing any work since that student can easily decide to avoid assignments due before the end of the term. But there can be no real freedom of choice without including the freedom to fail. Under the choice-of-work plan, the instructor must make himself available to students seeking assistance, but he should also be sure to impress upon them that they alone have the responsibility for planning their program and disciplining themselves to complete it. Encouraging student responsibility may be one of the most valuable features of the choice-of-work system

The choice-of-work approach to course organization presented here is much more important as a concept than as a detailed procedure. Any aspect of the system itself can be changed as the instructor chooses to alter the anount and quality of work involved; to encourage more or less examination-taking, paperwriting, oral performance, or whatever; or to provide work options of either a more or less traditional sort. All of these things can be done simply by adding or dropping options or by shifting point values. Regardless of the details of implementation, what is important is the principle of allowing students to choose for themselves what type of work they shall undertake for a course.

Providing choice of work cannot magically rescue an otherwise bad course, but it can often significantly strengthen a healthy one. The system is manageable, it is popular, and, most important; it is academically sound. A student ought to have the right to share in the process of dęciding how his or her mind is to be trained. Perhaps as a result, students will appreciate that there are various ways of learning which have equal value. That insight alone would justify giving students the opportunity to determine the nature of their own work. 